J. Dairy Sci. 94:537-537

doi:10.3168/jds.2011-94-1-537

(c) American Dairy Science Association ${ }^{\circledR}, 2011$.

\title{
Erratum to "Predictive ability of subsets of single nucleotide polymorphisms with and without parent average in US Holsteins" (J. Dairy Sci. 93:5942-5949)
}

\section{A. I. Vazquez, G. J. M. Rosa, K. A. Weigel, G. de los Campos, D. Gianola, and D. B. Allison}

An error was made in the presentation of data in Figure 2. The symbols used for Top.All and Top.All.PA were switched: the symbol for Top.All should be $\boldsymbol{\Lambda}$, and that for Top.All.PA should be $\Delta$. The corrected Figure 2 is presented below.
The authors regret this error.

Vazquez, A. I., G. J. M. Rosa, K. A. Weigel, G. de los Campos, D. Gianola, and D. B. Allison. 2010. Predictive ability of subsets of single nucleotide polymorphisms with and without parent average in US Holsteins. J. Dairy Sci. 93(12):5942-5949.

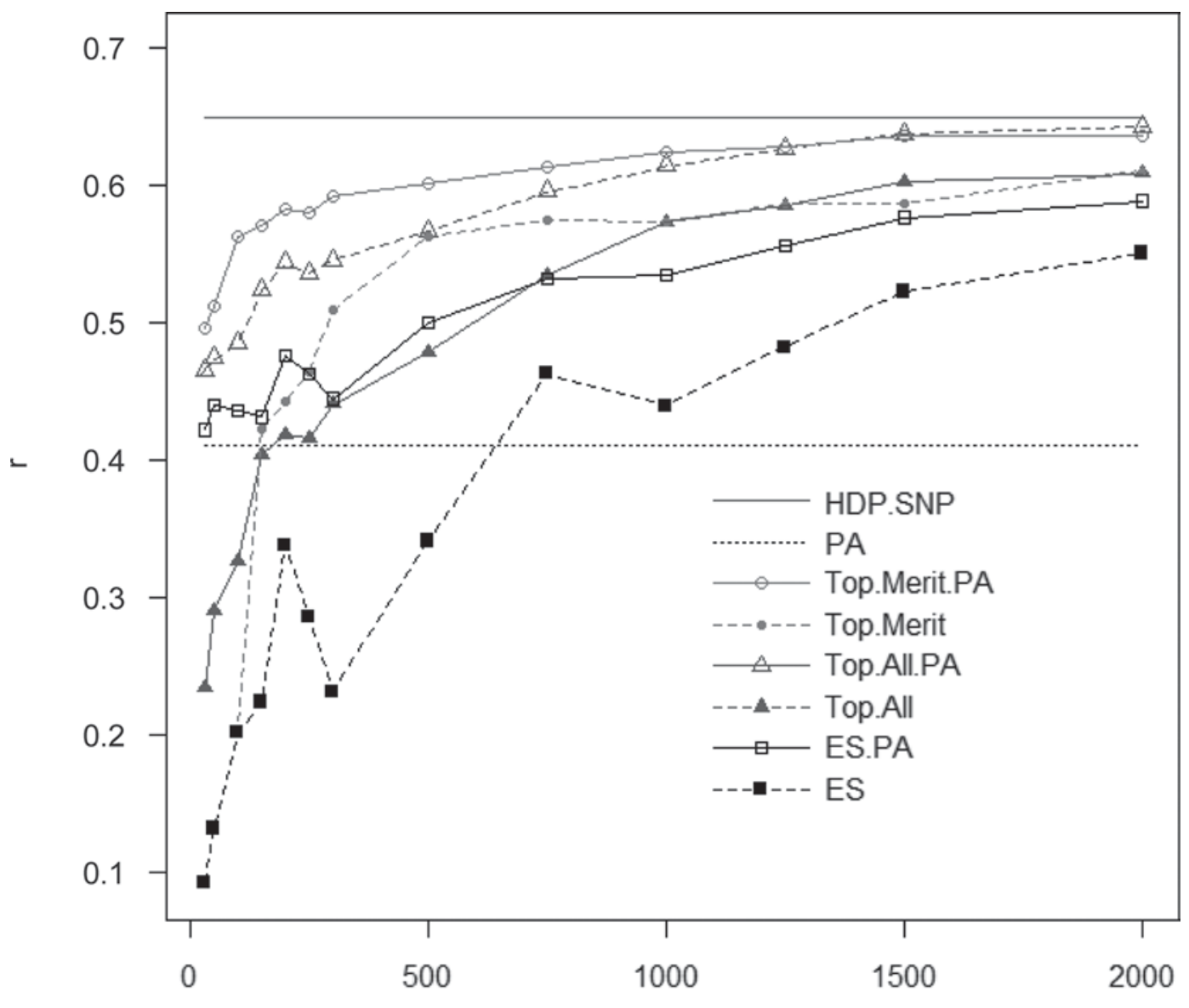

Number of SNP

Figure 2. Correlations between progeny-test PTA for net merit and genome-enabled predictions obtained with the high-density panel (HDP), the parent average (PA), the top SNP for HDP with (Top.Merit.PA) and without (Top.Merit) parent averages, the top SNP for 6 traits (milk, fat, protein, productive life, SCS, and daughter pregnancy rate) with (Top.All.PA) and without (Top.All) parent averages, and evenly spaced SNP with (ES.PA) and without (ES) parent averages, by set sizes of SNP. HDP.SNP $(-)$ and PA (...) have a fixed number of SNP. Color version available in the online PDF. 